\title{
O EFEITO DE INDETERMINAÇÃO: UMA DISCUSSÃO A PARTIR DA FORMAÇÃO DISCURSIVA DO DISCURSO PEDAGÓGICO
}

\author{
THE EFFECT OF INDETERMINATION: A DISCUSSION FROM THE DISCURSIVE \\ FORMATION OF PEDAGOGICAL DISCOURSE
}

\author{
Rosyane Mayre Pimenta Natal ${ }^{1}$ \\ ${ }^{1}$ Universidade Federal do Paraná (UFPR), Curitiba, PR, Brasil \\ Prefeitura Municipal de Curitiba (PMC), Curitiba, PR, Brasil \\ rosyane.fono@gmail.com
}

Recebido em 7 out. 2019

Aceito em 30 nov. 2019

Resumo: Neste estudo, buscamos pensar quais sentidos o efeito de indeterminação coloca em circulação no discurso pedagógico (ORLANDI, 2006). Mais do que isso, pretendemos discutir como estes sentidos emergem. Para tanto, é preciso mobilizar noções próprias do campo da análise de discurso francesa, indo além da materialidade linguística. Entendendo que o discurso é o lugar onde os sentidos se materializam, entendemos também que o discurso é um conceito teórico e metodológico que materializa o ideológico. Neste sentido, a Análise de Discurso não considera o discurso como simples transmissão de informação, mas sim como algo que coloca em relação os sujeitos e os sentidos. Em outras palavras, discurso é efeito de sentidos entre os sujeitos. O significado de um discurso será, então, constituído a partir das condições sócio-históricas em que foi proferido ou lido. $O$ efeito de indeterminação ocorre a partir de alguns elementos linguísticos. Tais elementos estabelecem relações intra e interdiscursivas. Discutiremos estas questões a partir da noção de terceira-pessoa discursiva, proposto por Indursky (1992), e do efeito de indeterminação do sujeito do discurso no interior do enunciado. Mobilizamos duas sequências discursivas que dizem respeito às falas de dois professores. Tais falas são tomadas como discurso, em um gesto interpretativo que é próprio da pesquisadora que se inscreve no campo teórico da Análise de Discurso. Os enunciados foram produzidos em uma situação de conversa entre a pesquisadora e os sujeitos participantes desta pesquisa, que faz parte de uma pesquisa maior, relativa ao processo de doutoramento da pesquisadora.

Palavras-chave: Discurso pedagógico. Sujeito-aluno. Sujeito-professor. Determinação. Terceirapessoa.

\begin{abstract}
In this study, we seek to understand what meanings the effect of indetermination places in the pedagogical discourse (ORLANDI, 2006). Moreover, we intend to discuss how these meanings emerge. Therefore, it is necessary to mobilize some concepts relevant to the French discourse analysis, going beyond linguistic materiality. Understanding that the discourse is where the senses materialize, we also understand that discourse is a theoretical and methodological concept that materializes the ideological. In this regard, Discourse Analysis does not consider discourse as a simple transmission of information, but rather as placing subjects and meanings in relation. In other words, discourse is the effect of senses among subjects. The socio-historical conditions will constitute the meaning of a discourse in which it was delivered or read. The indeterminacy effect occurs from some linguistic elements. Such elements establish intra and interdiscursive relations. We will discuss these issues from the discursive third-person notion proposed by Indursky (1992) and the indetermination effect of the discourse subject within the utterance. We mobilized two discursive sequences from the speeches of two teachers. Such speeches are taken as discourse, in an interpretative gesture that is typical of the researcher who is inscribed in the theoretical field of Discourse Analysis. The statements were produced in a conversation between the researcher and the subjects participating in this research, which is part of a larger research, related to the researcher's doctoral process.
\end{abstract}

Keywords: Pedagogical discourse. Subject-student. Subject-teacher. Determination. Third person. 


\section{ANÁLISE DE DISCURSO: NOS ENTREMEIOS ENTRE TEORIA E MÉTODO}

Nesta pesquisa, mobilizamos noções da Análise do Discurso (AD) a fim de trabalhar os sentidos a partir de uma materialidade específica: a fala de professores. Estas falas podem ser inscritas na formação discursiva do discurso pedagógico, conforme definido por Orlandi (2006). Elas foram produzidas em uma situação de conversa entre a pesquisadora e nove professores que estavam cientes da pesquisa ${ }^{1}$. As conversas foram gravadas em áudio e posteriormente transcritas. Produzimos uma análise a partir de um recorte que permite pensar quais sentidos o efeito de indeterminação coloca em circulação no discurso pedagógico. O recorte deu origem a duas sequências discursivas que contêm o efeito de indeterminação.

Antes, é preciso percorrer um breve percurso teórico. Isso porque o gesto de análise produzido pelo pesquisador que se inscreve na Análise de Discurso de filiação pecheutiana ocorre pela mobilização de diversas noções, dentre elas as noções de discurso (e seus tipos), ideologia, interdiscurso e formação discursiva. Estas noções se constituem umas em relação às outras, fornecendo ao pesquisador um instrumento de análise consistente. Por este motivo, o retorno teórico às noções ainda é constante nas pesquisas em Análise de Discurso e a mobilização destas noções é o que nos possibilita ir além da materialidade linguística.

A AD procura compreender a forma pela qual o discurso, visto enquanto objeto simbólico, produz sentidos. Esta compreensão parte de um gesto interpretativo. Interpretar em AD significa trabalhar nas margens da própria interpretação e compreender os mecanismos dos processos de significação. Assim, não há interpretação única, mas sim gestos de interpretação que permitem explicitar os sentidos e as formas pelas quais ele se constitui. Ao pesquisador, cabe formular a pergunta que vai direcionar a mobilização de conceitos diversos. Ele mobiliza o dispositivo teórico para desenvolver o seu dispositivo analítico (ORLANDI, 2001). Neste sentido, teoria e método estão intimamente relacionados, de modo que devemos passar pelas questões teóricas, ainda que de forma breve, antes de adentrar propriamente na questão da indeterminação no discurso pedagógico.

\footnotetext{
${ }^{1}$ Este corpus faz parte da pesquisa de doutorado da presente autora, pesquisa esta que foi submetida ao Comitê de Ética em Pesquisa em Seres Humanos da Universidade Federal do Paraná, tendo sido aprovada sob o parecer de № 2802095, na data de 06 de agosto de 2018.
} 
A AD tem como objeto específico o discurso enquanto efeito de sentidos entre os sujeitos (PÊCHEUX, 2010). Trata-se de um objeto que se constitui na materialidade linguística, mas esta por si só não garante a análise a que se propõe 0 analista de discurso. É preciso compreender que cada sequência discursiva está ligada a dizeres anteriores e, até mesmo, a dizeres futuros se pensarmos no jogo de imagens que os sujeitos estabelecem no momento da enunciação. Tais jogos pressupõem tanto o já dito como as possíveis implicações de seu dizer em outros dizeres. Isso significa que o histórico, o político e o inconsciente estão implicados em cada discurso que possa ocorrer, e em suas mais variadas formas. É por esses motivos que a $A D$ não toma como diretas as relações entre os sujeitos e a linguagem.

A exterioridade é apreendida pelos sujeitos pela via da linguagem. Falamos sobre as coisas, ou seja, significamos as coisas. As formas de significação vão variar de acordo com o tempo e o espaço histórico em que o sujeito está inserido. É nisto que se constitui a prática de ir além da materialidade linguística.

O discurso em foco neste trabalho é o discurso pedagógico, conforme definido por Orlandi (2006). Devemos ter em mente que as formas de constituição destes discursos estão atreladas a significados diversos: o 'ser professor' no tempo-espaço atual da educação brasileira, na escola pública; o 'ser aluno' no tempo-espaço atual da periferia, no período dos diagnósticos e medicalização da infância. Enfim, apenas alguns exemplos de aspectos a se considerar quando se pretende trabalhar com a formação discursiva do Discurso Pedagógico. Não se trata somente de contextualizar um discurso, mas sim de estabelecer relações, através de gestos interpretativos, com o já-dito e com o não dito, buscando seguir o fio do discurso, olhando para o processo de constituição do discurso. Em outras palavras, partimos do discurso e vamos ao encontro das condições de produção, das formações discursivas e dos sentidos.

Toda produção discursiva é sustentada pelas condições de produção, pelas relações de poder entre os sujeitos, pelas formações imaginárias, pelo efeito de préconstruído. Ainda, todo discurso remete a outro discurso, assim como todo sentido remete a outro sentido. Nisto consiste o interdiscurso, tal como trabalhado por Orlandi (1996, p. 80): "Algo fala sempre antes, em outro lugar, independentemente". Este algo que fala, fala sobre a dominação de uma formação ideológica (PÊCHEUX, 
2010). Ideologia e inconsciente estão aí relacionados, entre o sentido e o sujeito. Em outras palavras, a ideologia se manifesta através dos sujeitos que, por sua vez, encontram-se submetidos à ordem do inconsciente. É por essas vias (sujeitoideologia-inconsciente) que a linguagem, ou melhor, o discurso, por ser este exatamente o nosso objeto de pesquisa, perpetua sentidos através do tempo, inscrevendo-se na história. Podemos pensar, por exemplo, nos discursos que não se pretendem (consciente) preconceituosos, mas que, pela ideologia dominante, faz irromper (inconsciente) algo de outra ordem (o preconceito). Forma-se, portanto, uma memória social coletiva e, ao mesmo tempo, múltipla, fragmentada. A ideologia é entendida, em Pêcheux, como um dos princípios organizadores da formação discursiva (FD), juntamente com a noção de sujeito. Neste sentido, a FD expressa o que pode e deve ser dito a partir de determinada conjuntura ideológica. Pêcheux acredita que nenhum discurso é constituído ao acaso, mas sim que a ideologia é sempre uma força constitutiva dos discursos, e que a possibilidade de discurso ocorre na língua enquanto materialidade da qual emanam os efeitos de sentido. $\mathrm{E} o$ lugar da constituição dos sentidos é a FD. Segundo Pêcheux (2014), um mesmo sujeito pode ocupar diferentes posições no discurso e os sentidos não se originam nele (no sujeito). Os sentidos fazem parte de um conjunto maior, proveniente de determinada formação discursiva. Outra maneira de entender a FD é pensar que as palavras não têm seus sentidos nelas mesmas. O sentido se constitui a partir da FD à qual se filia a palavra dita. Sendo assim, uma mesma sequência discursiva pode apresentar sentidos diferentes se elas estiverem filiadas a FDs distintas.

Outra noção surge como determinante: a noção de formações imaginárias. Trata-se do imaginário construído a respeito de si mesmo e do outro, dos papéis que eu acredito desempenhar e que acredito serem desempenhados pelo outro, do que eu imagino que devo dizer e do que imagino que o outro espera que eu diga. Um discurso existe sempre em relação a outro discurso e em relação aos sujeitos da interlocução. Neste sentido, o imaginário é ideologicamente constituído nas diversas relações (de poder) exercidas pelos sujeitos. Todo sujeito pode colocar-se no lugar de seu interlocutor e isso afeta seu dizer, à medida que estabelece estratégias para alcançar os efeitos desejados. A imagem que os sujeitos produzem, não se refere ao sujeito empírico, mas sim à imagem da posição discursiva que ele ocupa. Desvincular o sujeito empírico de sua posição discursiva é importante para entender 
que 'lugar social' não coincide necessariamente com 'lugar discursivo'. Temos, por exemplo, a possibilidade de o indivíduo de classe baixa falar a partir da posição discursiva do indivíduo de classe alta (ORLANDI, 2001). Esta desvinculação do sujeito empírico do sujeito do discurso é fundamental em AD.

De acordo com Evandra Grigoletto (2008), os sujeitos ocupam lugares sociais, que têm a ver com a interpelação ideológica realizada a partir de uma formação social. Este lugar é empírico. Trata-se do lugar social ocupado pelo sujeito e que, através da forma-sujeito que se realiza no interior de uma FD, vai determinar seu lugar discursivo. Além disso, a própria estrutura da língua vai funcionar de forma a possibilitar que o sujeito ocupe determinado lugar discursivo. Assim, temos um jogo de afetações múltiplas, em que o lugar social determina o lugar discursivo ao mesmo tempo que a prática discursiva constitui os diversos lugares sociais. Um se constitui em relação ao outro. Nas palavras da autora,

os lugares discursivos são construídos pelo sujeito na sua relação com a língua e a história. Mas essa discursivização só acontece porque há uma determinação da formação social que institui determinados lugares, os quais podem e devem ser ocupados por sujeitos autorizados para tal. Por isso, este duplo efeito de determinação. O lugar social é efeito da prática discursiva, mas, ao mesmo tempo, o lugar discursivo também é efeito da prática social (GRIGOLETTO, 2008, p. 56).

Falando especificamente sobre o objeto desta pesquisa (o efeito de indeterminação no discurso pedagógico), a partir das noções de condição de produção, memória discursiva e formações imaginárias, temos que o sujeitoprofessor, ao formular seu discurso, é colocado em relação ao sujeito-aluno, em relação à sua própria prática e também em relação ao sujeito-pesquisador, que está diante dele no momento em que profere suas falas.

Por fim, é relevante abordar algumas características do discurso pedagógico. Segundo Orlandi (2006), o discurso pedagógico é caracterizado como predominantemente autoritário, pois nele a polissemia está contida, o referente está “ausente" (p. 29), os interlocutores são "apagados” (p. 29) e há um agente exclusivo. Nesse tipo de discurso, a utilidade e o interesse do interlocutor não estão em jogo. Ao contrário, os conteúdos apresentam-se como algo que se "deve" (p. 29) saber, no imperativo, e se instaura a noção de "erro" (p. 29). Isso ocorre devido ao modo de construção do discurso pedagógico, que se pretende representante do saber científico, objetivo e homogêneo. Trata-se de um dizer institucionalizado que se 
origina na Escola e que, em tese, existe para transmitir informação de forma neutra. No entanto, as condições de produção do discurso pedagógico apontam para a "contenção da polissemia" (p. 29), ou seja, não há rompimento e transformação de sentidos, apenas o "retorno constante a um mesmo dizer sedimentado" (p. 29), representado por um único agente, o professor, e que busca "estancar a reversibilidade" (p. 29).

O discurso pedagógico usa a cientificidade para se disfarçar de transmissor de informação, mas isto ocorre de forma a fixar definições, a produzir cortes polissêmicos e "encadeamentos automatizados que levam a conclusões exclusivas" (ORLANDI, 2006, p. 30). Deste modo, o professor não se mostra como o mediador do saber científico, mas sim como origem do próprio saber, equivalendo o saber e o dizer. É neste sentido que o discurso pedagógico aparece como "discurso do poder" (ORLANDI, 2006, p. 30): ele instaura a noção de erro ao mesmo tempo em que se coloca como detentor do saber.

Ao analisar os discursos dos professores, buscamos olhar também para o interdiscurso, pela via da memória discursiva que 'sustenta' os diferentes dizeres. Este tipo de análise ultrapassa o contexto imediato e a decomposição sintática, o que não significa excluir estes aspectos, mas sim tomá-los mediante os dispositivos teóricos fornecidos pela $A D$. As sequências discursivas mobilizadas neste estudo fazem parte de um conjunto de falas de professores, falas estas produzidas durante uma conversa entre professor e pesquisador. Esta conversa foi realizada em uma escola da rede pública de ensino de Curitiba e as sequências discursivas aqui trabalhadas referem-se às falas de professores do segundo (SD 1) e terceiro (SD 2) ano do ensino fundamental. As falas foram gravadas e posteriormente transcritas. Elas serão apresentadas acompanhadas de uma breve contextualização, para que seja possível ao leitor identificar qual era o tema da conversa naquele momento.

As condições de produção mais imediatas que compõem esta pesquisa estão relacionadas ao meu trabalho como fonoaudióloga da rede municipal de saúde de Curitiba, à escola, aos professores que participaram da entrevista e ao relacionamento que existe entre estes dois serviços, saúde e educação, no âmbito dos serviços públicos. O primeiro contato com a escola foi através de uma reunião com o setor pedagógico que, prontamente, permitiu que a pesquisa fosse realizada no interior da escola, com participação voluntária dos professores. Os professores 
eram convidados a participar da pesquisa durante o período de hora-atividade. $\mathrm{O}$ corpus aqui apresentado se refere às falas de dois professores e o gesto de análise se deu a partir de um recorte. Sendo assim, o que apresento nas análises não consiste na íntegra das transcrições, mas sim nos recortes produzidos a partir deste gesto que é, ele mesmo, parte do processo de análise. As sequências discursivas serão apresentadas e os gestos de análise produzidos buscando trabalhar os sentidos ali envolvidos de acordo com a temática proposta: os sentidos a partir do efeito de indeterminação.

Na formação discursiva do discurso pedagógico, as palavras têm seus sentidos funcionando em conformidade com tal FD, ou seja, seus sentidos se constituem dentro da própria FD. Assim, os discursos dos professores se constituem a partir de uma anterioridade, o já-dito, e dizem de uma determinação sócio-histórica.

Fazer uma leitura dos discursos pedagógicos significa produzir um gesto interpretativo. Isto nos conduz para uma compreensão sobre o que é ser criança, aprendiz, alfabetizando e, também, sobre o objeto 'escrita' enquanto objeto 'ensinável'. Neste sentido, podemos reconhecer aspectos importantes sobre os sentidos relacionados aos processos de ensino-aprendizagem, em uma sociedade que se faz na e pela linguagem, uma sociedade que se enuncia pela oralidade e pela escrita.

\section{O EFEITO DE INDETERMINAÇÃO NO DISCURSO PEDAGÓGICO}

A indeterminação é um efeito decorrente tanto da materialidade linguística, como da materialidade discursiva. Assim, alguns elementos linguísticos produzem o efeito de indeterminação a partir das relações intradiscursivas e interdiscursivas. A necessidade de pensar a questão da indeterminação no Discurso Pedagógico (DP) surgiu a partir de uma parte do corpus, mobilizado abaixo nas SDs 1 e 2 . Propusemos, então, a seguinte questão: quais sentidos são colocados em circulação a partir do efeito de indeterminação? Como a resposta a esta pergunta parte, inicialmente, da análise do pronome 'eles', faremos uma breve retomada a respeito desta materialidade linguística.

Émile Benveniste (2005) coloca em questão a universalidade da classe dos pronomes dizendo que o problema dos pronomes pode ser abordado como fato de 
linguagem e constituem-se, na verdade, não como classe unitária, mas como instâncias do discurso que se atualizam. Por 'se atualizam' entende-se que, cada vez que é proferido, o pronome referencia um ser, um único ser. Isto se aplica aos pronomes pessoais 'eu, tu, ele' que, conforme o exercício proposto por Benveniste, fazem parte de um processo pragmático que inclui não só o próprio signo, como a pessoa que o emprega. Neste sentido, não há sempre um mesmo 'eu' que se liga ao objeto, mas sim um 'eu' e um 'tu' que se estabelecem no discurso. 'Eu' é quem diz 'eu' a partir de uma determinada instância discursiva porque o 'eu' pode coincidir com o referente (quem diz), mas também pode estar contido no discurso enquanto algo referido (pensa-se no uso de aspas, por exemplo). Da mesma forma, o 'tu' refere-se ao indivíduo alocutado na instância discursiva. A instância discursiva é delimitada espacial e temporalmente (aqui, agora, hoje, amanhã etc.).

Neste sentido, tanto a categoria dos pronomes como a dos advérbios demonstrativos, devem ser tomados a partir da instância do discurso que contém o indicador de pessoa. Até agora, pensando nos pronomes 'eu' e 'tu', não temos problemas relacionados à unidade da classe conforme mencionado. Mas, ao abordar a categoria da terceira pessoa, Benveniste nos mostra que ela não funciona de modo a marcar 'quem' ou 'o que' da mesma forma que 'eu' e 'tu' o fazem. Neste sentido, 'ele' exerce uma função diferente da de 'eu' e 'tu' à medida que, na instância discursiva, são "substitutos abreviativos" (BENVENISTE, 2005, p. 282), da mesma forma que outros elementos de outras classes ${ }^{2}$. Em outras palavras, 'ele' referencia algo que pode ter exercido função de pessoa, mas ele próprio não exerce essa função. Por isso, 'ele' é chamado de 'não-pessoa'. Segundo Benveniste,

o que é preciso considerar como distintiva da "terceira pessoa" é a propriedade $1^{\circ}$ de se combinar com qualquer referência de objeto; $2^{\circ}$ de não ser jamais reflexiva da instância de discurso; 3ำ de comportar um número às vezes bastante grande de variantes pronominais ou demonstrativas; $4^{\circ}$ de não ser compatível com o paradigma dos termos referenciais como aqui, agora, etc." (BENVENISTE, 2005, p. 283).

Diferentemente do que propôs Benveniste sobre a terceira pessoa, ou a nãopessoa, Freda Indursky (1992) propõe pensar a terceira-pessoa discursiva como

\footnotetext{
${ }^{2}$ Benveniste cita o exemplo do verbo francês "faire": "cet enfant écrit maintenant mieux qu'il ne faisait l'année dernière". Neste caso o "faisait" exerce a função de representação sintática de partes do discurso proferido, sendo que não há nada que indique que "eu" e "tu" realizem função semelhante a esta, ao contrário de "ele".
} 
instância que participa da situação discursiva porque se institui como alteridade, ou seja, a terceira-pessoa discursiva só está aparentemente 'fora' da interlocução, pois o sujeito institui seu discurso instanciando a terceira-pessoa discursiva. Neste sentido, a terceira-pessoa discursiva não é 'de quem se fala', mas sim 'a quem se fala'. A terceira-pessoa discursiva é o interlocutor indeterminado, tornado presente na situação discursiva através do sujeito do discurso.

Analisando o processo de interlocução discursiva, Indursky (1992) apresenta uma diferença desta em relação à interlocução enunciativa. Ao contrário da interlocução enunciativa, na interlocução discursiva, tanto o sujeito do discurso como o interlocutor podem se representar em diversos níveis de especificidade, inclusive de modo indeterminado. A presença do interlocutor não necessariamente será clara, mas, ao mesmo tempo, não se anula, apenas ganha efeito de indeterminação. Isso é possível porque o locutor da cena enunciativa é definido como 'eu', enquanto na cena discursiva instaura-se o sujeito do discurso, categoria que tem um caráter mais opaco. A cena discursiva instaura um exterior não necessariamente imediato e presente fisicamente, mas sim instaurado através das diversas formações imaginárias possíveis.

$\mathrm{Na}$ cena enunciativa própria desta pesquisa, temos um locutor determinado (o professor) que dirige sua palavra a um interlocutor também determinado (o pesquisador), em uma situação bem específica (a participação na pesquisa) e em um espaço definido (a escola). No entanto, se pensarmos do ponto de vista proposto por Indursky (1992), a cena discursiva instaura um sujeito-professor que é afetado pela FD de referência (a do discurso pedagógico). Isso significa que os discursos ali proferidos não são pessoais, mas sim historicamente determinados. Neste sentido, os sujeitos que participaram da entrevista podem ser considerados como sujeitoprofessor vinculados a uma mesma FD do discurso pedagógico (que pode não ser a única, mas que é a principal para a pesquisa). Da mesma forma, um interlocutor (a pesquisadora, no nosso caso) pode não ser único, já que a opacidade da cena discursiva pode esconder a instauração de um outro interlocutor, invisível.

A sequência discursiva exposta a seguir foi enunciada a partir da seguinte temática: pesquisadora e professora conversam sobre as diretrizes curriculares para alfabetização no município de referência. Vejamos a SD 1: 
SD 1: Olha, eu não sei sabe, não sei direito o que pensar porque... bom eu acho tudo uma grande besteira porque eles vem dizendo que tem que ser assim-assado, mas não sabem, não conhecem a realidade. É tudo muito bonito no papel, mas na sala de aula é um deus nos acuda.

Este discurso foi constituído a partir da instanciação da terceira-pessoa discursiva, o 'eles'. Ao mesmo tempo, foi constituído para a terceira-pessoa discursiva, ou seja, ela foi tornada presente na situação discursiva a partir das formações imaginárias. O que há é um efeito de indeterminação, tendo em vista que o 'eles' não foi previamente referenciado. A respeito da determinação/indeterminação, ainda de acordo com Indursky (1992), temos que a determinação discursiva é um efeito de sentido decorrente de fatores sintáticos, semânticos e ideológicos. As categorias adjetivo e sintagma preposicional, por exemplo, podem ser determinantes do ponto de vista discursivo já que trabalha de modo a dar sentido ao substantivo a partir de uma determinada FD. Nas palavras da autora, "o sujeito é compelido, pela formação discursiva que o afeta, a saturar o substantivo [...] pois os determinantes linguísticos que precedem o nome não são suficientes para determinar o seu dizer" (INDURSKY, 1992, p. 262).

Ao dizer que os determinantes discursivos ocorrem por um efeito de sentido ideológico, além de sintáticos e semânticos, Indursky sugere que o sujeito do discurso determina seu dizer de forma nem totalmente livre, nem totalmente assujeitada. Nem totalmente livre porque é interpelado, pela formação discursiva que o afeta, a preencher os sentidos relativos ao substantivo. Nem totalmente assujeitado porque realiza uma seleção de sintagmas a serem utilizados neste preenchimento de sentidos. Desta condição decorre que a determinação discursiva é muito mais ideológica do que estilística. Citando Claudine Haroche, Indursky (1992) explica que os processos de determinação discursiva permitem o vislumbre, na materialidade linguística, do sujeito e de sua posição no discurso.

Indursky propõe, a partir de seu corpus, a decomposição dos processos de determinação discursiva em três níveis:

(1) nível intradiscursivo, quando o dito é plenamente determinado, estabelecendo o limite do dizer; (2) nível intersequencial, quando as diferentes determinações intradiscursivas dispersas no corpus evidenciam a construção de um processo discursivo; (3) nível interdiscursivo, quando o intradiscurso é relacionado com o interdiscurso, e o dito passa a fazer contraponto com o não-dito (INDURSKY, 1992, p. 264). 
Ao analisar a determinação discursiva no nível intradiscursivo, ou seja, no interior da sequência discursiva, a autora observa que a saturação dos substantivos é que assegura, imaginariamente, a manutenção do sentido pretendido pelo sujeito, seguindo certa coerência ideológica. Quando a análise se volta para um conjunto de determinações discursivas dispersas no corpus, no nível intersequencial, a autora observa a extensão da saturação do substantivo de forma a construir uma determinada significação, também em conformidade com a formação discursiva de referência. Já no nível interdiscursivo, a autora olha para as possíveis relações que uma determinada sequência discursiva estabelece com seu exterior constitutivo. Neste nível, é possível notar que a saturação de um substantivo só é plena no intradiscurso de forma ilusória, pois elementos do interdiscurso aí evocados podem contribuir para um outro tipo de saturação que envolve a contradição e o não-dito. Neste sentido, ao passar do nível intradiscursivo para o interdiscursivo, a completude dá lugar à incompletude.

Os três níveis descritos podem estar correlacionados instaurando-se uma "multi-saturação" (INDURSKY, 1992, p. 278). Quando isso ocorre, instaura-se o processo de sobredeterminação discursiva. Em outras palavras, o que a autora explica é que a sobredeterminação ${ }^{3}$ (termo deslocado da psicanálise e de Althusser) ocorre no discurso a partir da acumulação de determinações sucessivas entre os três níveis.

Com o que foi exposto até aqui, já podemos compreender por que a falta de referência prévia ao 'eles' na SD 1 não impede o preenchimento de sentido. Interpretamos que o 'eles' se refere às instâncias educacionais que orientam a prática pedagógica, como por exemplo, as diretrizes curriculares elaboradas pela Secretaria Municipal de Educação. A terceira-pessoa é indeterminada do ponto de vista sintático, mas determinada do ponto de vista semântico e ideológico. Trata-se de um elemento não expresso na materialidade linguística, pois, na formação discursiva do discurso pedagógico, a crítica ao sistema não é bem-vinda. Substantivar o 'eles' seria da ordem do 'o que não convém dizer' a partir da

\footnotetext{
${ }^{3}$ A noção de "sobredeterminação" tem sua origem na psicanálise e, posteriormente, Althusser a utiliza para tratar da contradição marxista. Indursky propõe um deslocamento da noção de sobredeterminação para as questões do discurso, pois, conforme explica a autora, a determinação discursiva leva a determinações sucessivas (Cf. INDURSKY, 1992, p. 282-283).
} 
formação discursiva do discurso pedagógico. Assim, o efeito de indeterminação faz parte de um não-dito.

Além do efeito de indeterminação em decorrência do que não convém ser dito na formação discursiva do discurso pedagógico, podemos ter um efeito de indeterminação em decorrência da necessidade do sujeito se distanciar da crítica que ele está promovendo. O enunciado abaixo foi proferido quando o professor falava sobre as dificuldades da prática alfabetizadora. Vejamos:

SD 2: a gente percebe várias falhas na alfabetização, são problemas de falhas que houveram na alfabetização, por exemplo, eu tenho uma aluna que ela troca o " $M$ " ou o " $N$ " pelo " $R$ ", então se ela for escrever "mundo" ela escreve "murdo", então são falhas na alfabetização. Então para você desconstruir isso é difícil.

$\mathrm{Na}$ materialidade linguística da SD 2 temos o emprego dos substantivos "falhas", "problemas" e "alfabetização", seguidos por um exemplo de como tais substantivos devem ser entendidos ("eu tenho uma aluna que ela troca..."). Trata-se de uma tentativa do sujeito de assegurar um certo sentido, em conformidade com a formação discursiva do discurso pedagógico, que tende a direcionar a crítica para o sujeito-aluno. Tentativa porque assegurar um sentido só é imaginariamente possível. Se, além dos substantivos, considerarmos o verbo "houveram", e pensarmos no exterior constitutivo deste discurso, interpretamos que há aí um não-dito expresso pela não implicação do sujeito responsável pelas "falhas que houveram na alfabetização". Assim, apesar de uma referência direta ao sujeito-aluno ("eu tenho uma aluna...") no intradiscurso, há uma incompletude causada pelas relações interdiscursivas próprias da FD do discurso pedagógico. Assim, "houveram" provoca o efeito de sentido de que as falhas na alfabetização ocorrem por elas mesmas, sem um agente. O funcionamento discursivo não instaura um sujeito, mas deixa-o indeterminado, ou seja, não implica ninguém. Este efeito de indeterminação decorre do apagamento de si (o sujeito do discurso) no momento que se está produzindo uma crítica. 


\section{EFEITO DE FECHAMENTO}

A partir do corpus mobilizado e do aparato teórico fornecido pela $A D$, foi possível trabalhar os sentidos em relação ao efeito de indeterminação no discurso pedagógico. Na SD 1 vimos que a instanciação da terceira-pessoa discursiva se deu a partir do pronome 'eles' e que o efeito de indeterminação ocorreu devido a ausência de referenciação prévia, ou seja, a terceira-pessoa se manteve indeterminada do ponto de vista sintático. Já do ponto de vista semântico e ideológico, o interlocutor consegue preencher o sentido de 'eles'. Levando em consideração que, na formação discursiva do discurso pedagógico, a crítica ao sistema não é bem-vinda, interpretamos que deixar de substantivar o 'eles' faz parte do funcionamento de um não-dito que seria da ordem do que não convém dizer.

Na SD 2 vimos que o sujeito do discurso pode usar da indeterminação para se distanciar da crítica que está promovendo. Interpretamos que o direcionamento da crítica para o sujeito-aluno ocorre de maneira bem marcada no discurso do professor ao passo que a crítica ao sistema de ensino permanece indeterminada no enunciado "falhas que houveram na alfabetização". Temos, portanto, efeito de apagamento do agente responsável pelas 'falhas'.

Discutimos que o sujeito-professor implica o sujeito-aluno, mas não implica a si mesmo e nem uma instituição específica no momento em que expõe as dificuldades relacionadas à prática alfabetizadora. Vale lembrar que o sujeito-professor produz seus discursos em conformidade com a formação discursiva do discurso pedagógico que, por sua vez, determina o que pode ser dito a partir de determinadas condições históricas e ideológicas. Este gesto interpretativo foi possível a partir da mobilização de noções como as de formação discursiva, interdiscurso, sujeito do discurso, formações imaginárias e, principalmente, a partir do trabalho de Indursky (1992) com a noção de terceira-pessoa discursiva e determinação/indeterminação. Percebe-se a importância de olhar para a materialidade linguística como objeto que aponta para a exterioridade. Em outras palavras, não deixamos de lado o aspecto sintático, mas sim olhamos para ele a partir dos dispositivos que a análise de discurso fornece, ou seja, tomando a materialidade linguística como discurso de onde emanam sentidos diversos, sentidos estes que podem ser muitos, mas não qualquer um. 


\section{REFERÊNCIAS}

BENVENISTE, E. Problemas de Linguística Geral I. Tradução de Maria da Glória Novak e Maria Luisa Neri. 5. ed. Campinas: Pontes Editores, 2005.

GRIGOLETTO, E. Do lugar discursivo à posição-sujeito: os movimentos do sujeitojornalista no discurso de divulgação científica. In: MITTMANN, S.; GRIGOLETTO, E.; CAZARIN, E. A. (org.) Práticas discursivas e identitárias: sujeito e língua. Porto Alegre: Nova Prova, 2008.

INDURSKY, F. A fala dos quartéis e as outras vozes: uma análise do discurso presidencial da terceira república brasileira. 1992. Tese (Doutorado em Ciências) Instituto de Estudos da Linguagem, Universidade Estadual de Campinas, Campinas, 1992.

MITTMANN, S.; GRIGOLETTO, E.; CAZARIN, E. A. (org.). Práticas discursivas e identitárias: sujeito e língua. Porto Alegre: Nova Prova, 2008.

ORLANDI, E. P. A linguagem e seu funcionamento: as formas do discurso. Campinas: Pontes, 2006.

ORLANDI, E. P. Análise de Discurso: princípios e procedimentos. Campinas: Pontes, 2001.

ORLANDI, E. P. Interpretação: autoria, leitura e efeitos do trabalho simbólico. Petrópolis: Vozes, 1996.

PÊCHEUX, M. Análise automática do discurso (AAD-69). In: GADET, F.; HAK, T. (org.). Por uma análise automática do discurso: uma introdução à obra de Michel Pêcheux. Tradução de Bethânia Sampaio Corrêa Mariani et al. 4. ed. Campinas: Editora da Unicamp, 2010. p. 59-158.

PÊCHEUX, M. Semântica e discurso: Uma crítica à afirmação do óbvio. Tradução de Eni P. Orlandi et al. 4. ed. Campinas: Editora da Unicamp, 2014.

\section{Sobre a autora}

\section{Rosyane Mayre Pimenta Natal}

Doutoranda em Letras na Universidade Federal do Paraná. Possui mestrado em Letras, ênfase em Estudos Linguísticos, pela Universidade Federal do Paraná (2014) e graduação em Fonoaudiologia (bacharelado) pela Universidade Estadual do Centro-Oeste (2009). Atualmente, dedica-se aos estudos do discurso em uma abordagem pecheutiana. Tem experiência nas áreas de clínica de linguagem, com ênfase em aquisição da linguagem oral e escrita, estimulação precoce e atuação fonoaudiológica na rede SUS, mais especificamente em NASF (Núcleo de Apoio à Saúde da Família). 